\title{
WAGES, MINIMUM WAGES, AND PRICE PASS-THROUGH: THE CASE OF MCDONALD'S RESTAURANTS
}

\author{
Orley C. Ashenfelter \\ Štěpán Jurajda \\ Working Paper 28506 \\ http://www.nber.org/papers/w28506 \\ NATIONAL BUREAU OF ECONOMIC RESEARCH \\ 1050 Massachusetts Avenue \\ Cambridge, MA 02138 \\ February 2021
}

Our McDonald's survey was collected in phone interviews by ISA Corp under exemption \#7779 granted by the Princeton University Institutional Review Board for Human Subjects. We would like to thank Daniel Aaronson, Barry Hirsch, Nikolas Mittag and participants at the (virtual) Memorial Conference celebrating Alan Krueger for their helpful comments. Marin Drlje provided excellent research assistance. The views expressed herein are those of the authors and do not necessarily reflect the views of the National Bureau of Economic Research.

NBER working papers are circulated for discussion and comment purposes. They have not been peer-reviewed or been subject to the review by the NBER Board of Directors that accompanies official NBER publications.

(C) 2021 by Orley C. Ashenfelter and Štěp án Jurajda. All rights reserved. Short sections of text, not to exceed two paragraphs, may be quoted without explicit permission provided that full credit, including $\odot$ notice, is given to the source. 
Wages, Minimum Wages, and Price Pass-Through: The Case of McDonald's Restaurants Orley C. Ashenfelter and Štěpán Jurajda

NBER Working Paper No. 28506

February 2021

JEL No. J23,J30,J38

\begin{abstract}
$\underline{\text { ABSTRACT }}$
We use price and wage data from McDonald's restaurants to provide evidence on wage increases, labor-saving technology introduction, and price pass-through by a large low-wage employer facing a flurry of minimum wage hikes from 2016-2020. We estimate an elasticity of hourly wage rates with respect to minimum wages of 0.7 . In $40 \%$ of instances where minimum wages increase, McDonald's restaurants' wages are near the effective minimum wage level both before and after its increase; however, we also uncover a tendency among a large subset of restaurants to preserve their pay 'premium' above the minimum wage level. We find no association between the adoption of labor-saving touch screen ordering technology and minimum wage hikes. Our data imply that McDonald's restaurants pass through the higher costs of minimum wage increases in the form of higher prices of the Big Mac sandwich. We find a 0.2 price elasticity with respect to wage increases, which implies an elasticity of prices with respect to minimum wages of about 0.14. Based on a listing of all US McDonald's restaurants from 2010 to 2020, we also find no effects of minimum wages on McDonald's restaurant entry and exit.
\end{abstract}

Orley C. Ashenfelter

Industrial Relations Section

Louis A. Simpson International Bldg.

Room 258

Princeton University

Princeton, NJ 08544

and NBER

c6789@princeton.edu

Štěpán Jurajda

CERGE-EI

Politickych veznu 7

Prague, 11000

Czech Republic

stepan.jurajda@cerge-ei.cz 


\section{Introduction}

Minimum wage legislation aims at raising real incomes of low-wage workers, most of whom are employed in the retail and hospitality industries. In this paper, we offer evidence on minimum wages from a new data set we have collected covering almost all of the US restaurants in the McDonald's chain.

The pay levels in McDonald's restaurants, the largest U.S. franchise chain, are powerfully affected by minimum wage legislation. ${ }^{1}$ McDonald's restaurants are highly standardized in terms of technology and working conditions, which facilitates the cross-area and cross-time comparisons involved in the study of minimum wage effects. ${ }^{2}$

We first use our rich, highly consistent national-coverage data to study the structure of wage increases in response to minimum wage hikes. The flurry of minimum wage increases at the state and local level in the last few years provides us with a natural workshop for studying their effects. Based on information on the hourly wage rates of McDonald's Basic Crew from about 10 thousand restaurants observed annually from 2016 to 2020, we estimate an elasticity of hourly wage rates with respect to minimum wages of about 0.7 . Surprisingly, this elasticity is the same for restaurants for which minimum wage increases were binding and those that were not. Underneath this elasticity, there are heterogeneous wage responses: In almost $40 \%$ of instances when minimum wages increase, McDonald's restaurants' wages are near the effective minimum wage level both before and after its increase. Such wage paths are consistent with the simple neoclassical model of labor markets. However, in a similarly large group of instances, restaurants increase their pay more than required by the increase in minimum wages. We document a tendency among these restaurants to preserve their pay 'premium' above the (increasing) minimum wage level. This suggests cross-employer pay norms are important even in entry-level low-skilled jobs; future research is needed to understand the source of these norms.

\footnotetext{
${ }^{1}$ In 2016 almost half of McDonald's Basic Crew wage rates in the US were equal to the effective local minimum wage level, i.e., at the maximum of the federal, the state, and the local minimum wage.

${ }^{2}$ It is plausible that McDonald's restaurants react to higher labor costs in part by adjusting the quality of service or the cleanliness of the restaurants. However, such adjustments are limited by the nature of the detailed operating manual, which is designed to minimize costs to the brand name. In addition, the highly regimented operation of McDonald's restaurants allows for little variation in the labor share.
} 
We then study whether employers substitute capital for labor when the price of low-skill labor increases due to minimum wage hikes. To provide insight into this issue within the fast food industry, we study a recently developed labor-saving technology in McDonald's restaurants: the introduction of touch-screen ordering kiosks. These were available in one fifth of McDonald's restaurants in 2017, but were available in close to three-fourths by 2019. Our data do not indicate that the introduction of this technology was related to minimum wage increases. This evidence is not consistent with technology introduction being a channel for negative employment effects of minimum wages.

Next, we measure the ability of McDonald's restaurants to pass through the higher costs of labor induced by changes in minimum wages during 2016 to 2020 onto their customers in the form of higher prices of the Big Mac sandwich. We use minimum wages increases as instrumental variable and find a 0.2 price elasticity with respect to wage increases. Together with the 0.7 (firststage) elasticity of wage rates with respect to minimum wages, this implies a reduced-form elasticity of prices with respect to minimum wages of about 0.14 . We uncover a full or near-full price pass-through of minimum-wage-induced higher costs of labor and find no evidence that this pass-through elasticity varies with exposure to minimum wage increases or across varying degrees of product market competition.

Finally, we employ a listing of all US McDonald's restaurants from 2010 to 2020 to estimate the effects of minimum wages on McDonald's restaurant entry and exit. We find no effects on either entry or exit based on various identification strategies. This implies that our analyses of wage effects and price pass-through are not influenced by the composition of the restaurants in our sample.

Unlike Card and Krueger's (1994, 1995) seminal work, we do not offer evidence on employment effects of the minimum wage. Our findings do not rule out employment effects, but our evidence on wage increases, technology introduction, and price pass-through is consistent with studies that find no or small minimum-wage employment effects in the fast food industry. 


\section{US McDonald's in Our Data}

During 2010-2020, there were about 14 thousand McDonald's restaurants in the US according to our first data source - the annual geo-coded listing of all McDonald's restaurants, which includes information on restaurant type (freestanding vs. part of a mall or Walmart). ${ }^{3} \mathrm{We}$ rely on this listing in our restaurant entry/exit analysis and we also use it as the population for our 2016-2020 annual telephone survey of McDonald's restaurants, our second data source. In the survey, we collect prices of the Big Mac sandwich (including sales tax and excluding temporary promotions) and wage rates of the Basic Crew (for day shift entry-level crew members aged 18 or older who finished initial training), which we will refer to as McWages. In 2016, the survey collected information from $80 \%$ of all US McDonald's restaurants and coved 2,255 US counties with $97 \%$ of the US population. The restaurant coverage rate gradually declined from $80 \%$ in 2016 to $71 \%$ in 2020 , but the data cover at least $90 \%$ of US counties with a McDonald's in every year of the survey thanks to a generally high response rate. Across the five survey years, there are 52,281 restaurant-year observations. ${ }^{4}$ In Ashenfelter and Jurajda (2020), we introduce the survey in more detail and use repeat interviews to estimate the annual reliability ratio of McWages and Big Mac prices to be at least 0.9 . and 0.7 , respectively. ${ }^{5}$ Finally, we supplement the survey with the 2018 complete list of McDonald's franchises with owner identity ${ }^{6}$ to classify restaurants as franchised or company-owned (10\% are), and to calculate local-market indices of ownership concentration.

The structure of the McWage survey data is stable with about $10 \%$ of restaurants being company-owned in each year of the survey, $86 \%$ being free-standing restaurants, $13 \%$ being located along highways or parkways, and with $4 \%$ of the interviews being answered by a Basic Crew member (as opposed to a manager). This stability corresponds to the high response rates of our survey and the low 1.0\% entry and exit rate averages measured from the 2010-2020 listing of McDonald's restaurants (see Appendix Tab A.1 and Fig. A.1).

The period from 2010 to 2020 saw a flurry of minimum wage increases across the US. Most of the three hundred increases in state or local minimum wage levels during this period

\footnotetext{
${ }^{3}$ The database was obtained from AggData, a market research company.

${ }^{4}$ Of these, only 720 observations come from stores that are observed only once.

${ }^{5}$ The reliability ratio corresponding to annual wage changes is also about 0.9 .

${ }^{6}$ The database was obtained from FranData, a market research company.
} 
occurred during 2016-2020, the period for which we have collected wage and price data. ${ }^{7}$ There are 42 cities with McDonald's restaurants covered by our data that have a local minimum wage ordinance in place by 2020 . The simple cross-state average of effective state minimum wages increases from $\$ 7.43$ in 2010 to $\$ 9.20$ in 2020 . The average effective local minimum wage across the locations with McDonald's that by 2020 have a local minimum wage ordinance increases from $\$ 7.90$ in 2010 to $\$ 13.90$ in 2020 . Despite this growth in minimum wages, the share of McWages that are censored at the local effective minimum wage declines (by 3 to 5 percentage points annually from $45 \%$ in 2016 to $30 \%$ in 2020 ).

To what extent do restaurant characteristics explain differences in McWages and Big Mac Prices across restaurants? The answer is, not much. In columns (1) to (4) of Table 1, we use least squares regressions to measure the explanatory power of restaurant characteristics, McWages, and state sales tax levels for the cross-restaurant variation in prices of the Big Mac. Freestanding restaurants, i.e., those that are not part of a mall or a Walmart, have prices that are about $1-2 \%$ lower, both across and within states, as documented in the first two columns of Table 1, which is based on 2018, a mid-year of our survey. The results based on other years are similar. Prices comove across locations in tandem with local sales taxes (including state sales taxes and measured as shares, i.e., $8 \%$ expressed as 0.08 ). In recent years, touch-screen ordering has been gradually introduced in most McDonald's restaurants (see Appendix Table A.1). Our survey asks about the presence of touch-screen ordering starting in 2017. In Table 1, we find a precisely estimated zero price coefficient corresponding to this new technology in 2018 (estimates from other years are nearly identical). In the absence of state fixed effects, we can explain only about $5 \%$ of the variation in Big Mac prices across restaurants in column (1). There is clearly much unexplained cross-restaurant variation in prices. Even conditioning on McWages and on over two thousand county fixed effects does not increase the (adjusted) $\mathrm{R}^{2}$ of the price regression above $0.5 .^{8}$

\footnotetext{
${ }^{7}$ For the purposes of our analysis, we consider Washington, D.C., which has more McDonald's than Vermont or North Dakota, as a US state. Our information on state and local minimum wages comes primarily from the Department of Labor and the Berkeley Labor Center. We have updated the most recent local minimum wage ordinances ourselves.

${ }^{8}$ The US-wide price variation is similar in franchised and in company-owned restaurants. The McDonald's chain therefore does not apply uniform pricing, unlike grocery chains (DellaVigna and Gentzkow, 2019).
} 
Tab. 1: Explaining $2018 \ln$ (BigMacPrice) and $\ln$ (McWage) using Restaurant Characteristics

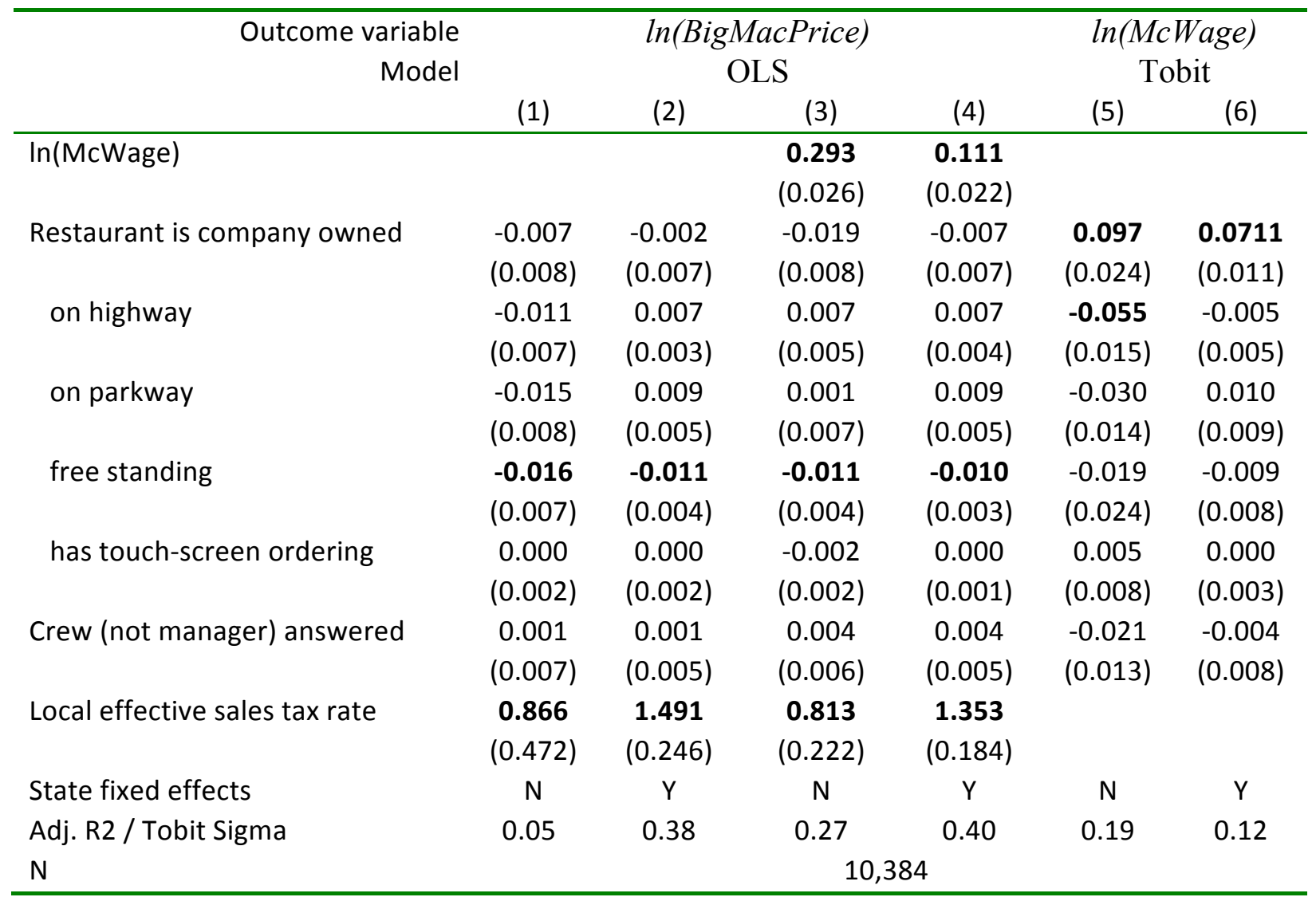

Note: Standard errors in parentheses are based on clustering of residuals at the state level. Bolded coefficients are statistically significant at the $1 \%$ level.

In columns (5) and (6) of Table 1, we ask whether restaurant characteristics explain variation in McWages using a Tobit specification with variable censoring thresholds corresponding to the effective (state, county, or city) minimum wage levels. Consistent with Krueger's (1991) early work, company-owned restaurants pay higher wage rates than franchised restaurants. Touchscreen ordering is not associated with wage differences across restaurants. Overall, restaurant characteristics explain little of the overall variation as confirmed by the Tobit sigma (estimated standard error of the residuals) in Table 1, which decreases by less than. 01 when restaurant characteristics are added to either specification. Avoiding the censoring issue and using only 
observations that are strictly above the effective minimum wage level, the adjusted $\mathrm{R}^{2}$ of a linear regression corresponding to the specification presented in column (5) of Table 1 is $0.02 .^{9}$

What is the labor cost share in McDonald's restaurants? Our understanding of McDonald's production technology is based on the McDonald's extensive operations manual and on the company's global warranty of producing identical products using standardized technology. Aaronson et al. (2018) assume that these fast food restaurants operate a Leontief production function where inputs are used in fixed proportion (without substitution) and average variable costs equal marginal costs. Approximating the relationship between prices and wages, the cross-sectional regression of $\ln$ (BigMacPrice) on $\ln$ (McWage) in column (3) of Table 1 would suggest a 30\% share

of labor costs in Big Mac prices. ${ }^{10}$ Consistent with this estimate, Dube et al. (2010) suggest that the labor share in operating costs in the US restaurant sector is about $30 \%{ }^{11}$

\section{Theory and Empirical Literature}

Our analysis is related to four distinct parts of the minimum wage literature, which reflects alternative assumptions about the type of labor market and product market competition faced by employers who react to higher labor costs due to minimum wage legislation. Although Card and Krueger (1994) did not find evidence of any spillover of minimum wage increases on other wages, subsequent work has documented that minimum wage hikes are often associated with a positive spillover (or "ripple effect") on wages above the new minimum. The research measuring such ripple effects (e.g., Cenzig et al., 2019) often refers to models featuring labor market frictions, where such wage spillovers may reflect the value of outside options or within-firm pay norms (Flinn 2006). Our McWage evidence, which focuses on highly comparable jobs, speaks to across-

\footnotetext{
${ }^{9}$ In $2020,84 \%$ of the surveyed restaurants operate only through drive-through and delivery service due to the Covid-19 pandemic. In specifications corresponding to Table 1, we find precisely estimated zero coefficients of these operation restrictions on prices as well as wages when conditioning on state fixed effects. This conclusion is not affected by instrumenting for the presence of operation restrictions using county-level Covid-19 deaths until the end of September 2020.

${ }^{10}$ When we additionally condition on the effective minimum wage level (state and local), the minimum wage coefficients correspond to about half of the McWage coefficient from column (3) of Table 1.

${ }^{11}$ Under the additive input costs assumption, Parsley and Wei (2007) use international (city-level) price data on the Big Mac and all of its inputs (ingredients, rents, energy, and labor) to find that labor is by far the most important non-tradable cost, with minimal cost shares of energy and rent.
} 
firm comparisons (pay norms) for workers providing a specific skill input under fixed hedonic job properties. It thus limits the applicability of some of the mechanisms for spillovers considered in the literature (e.g., Phelan, 2019).

The research studying the susceptibility of low-wage employment to technological substitution typically employs the task-based empirical framework. In a recent study, Aaronson and Phelan (2019) rely on minimum wage increases for plausibly exogenous variation in labor costs and find that the potential for technological substitution of low-skill labor is limited to cognitively routine tasks, i.e., it may not apply to manually routine jobs. ${ }^{12}$ The advantage of our setting is that we have a direct measure of the introduction of a labor-saving technology in the form of touchscreen ordering (kiosks) in fast-food restaurants, which are facing a flurry of minimum wage hikes. We thus ask whether the timing of the technology introduction corresponds to increases in labor costs. Our analysis is narrow in that it focuses on one company, but it offers highly consistent comparisons across the geographical distribution of minimum wage increases.

The literature focusing on the price pass-through of minimum wages considers imperfect product as well as labor markets. Under monopsonistic competition in local labor markets, firms face an upward sloping labor supply curve (Manning, 2003). A small increase in minimum wages raises employment, and hence output and lowers prices, while a large increase in minimum wages cuts employment and output, and increases prices, similar to the case of fully competitive markets. An important insight for our analysis is that with constant returns to scale, firms adjust prices in response to minimum wage hikes in proportion to the cost share of minimum-wage labor (e.g., Leung, in press). If both labor and product markets are competitive, firms can pass through up to the full increase in costs (Fullerton and Metcalf, 2002). More generally, demand elasticity and demand convexity are (potentially location-specific) determinants of the pass-through (Weyl and Fabinger, 2013). Pless and van Benthem (2019) argue that under specific conditions, a passthrough rate above unity suggests the existence of market power.

There is a growing empirical literature on the price pass-through effects of minimum wages. ${ }^{13}$ Much of the recent work in this area relies on food CPI indices measured at the regional

\footnotetext{
${ }^{12}$ There is closely related evidence from outside of the US. For example, Hau et al. (2020) find that in privately-owned Chinese firms minimum wage hikes accelerate input substitution from labor to capital. ${ }^{13}$ Card and Krueger (1994) is an early study focusing on the fast food industry. Much research studies the cost pass-through rate in retail: Ashenfelter et al. (1998) estimate the rate for a single retail chain. Recent
} 
(e.g., MSA) level (Aaronson, 2001; Aaronson and French, 2007; Aaronson et al., 2008). The study of Basker and Khan (2016) is closely related to our analysis in that it uses 1993-2014 McDonald's Quarter-Pounder prices from about 300 US cities to uncover a 0.09 price elasticity. To learn about the degree of pass-through, Basker and Khan estimate the effect of the minimum wage on all limited-service restaurant wage bills across cities, find it to be about twice the size of the price pass-through elasticity, and argue that if the labor share of costs is about 50\%, restaurants are fully passing through their cost increases to consumer prices. Similarly, Allegretto and Reich (2018) imply a near-full price pass-through of higher labor costs in internet-based restaurants in San Jose, CA. The simplest explanation for these full price pass-through findings is that both fast-food product and labor markets are competitive. Two recent analyses that also support the presence of significant price pass-through are able to exploit confidential restaurant-level payroll data from a restaurant chain: Hirsch, Kaufman, and Zelenska (2015) and Brummund (2017) use information on 80 and 515 restaurants covering 2 and 13 states, respectively. Their results are consistent with no significant employment or hours effects of minimum wage hikes even in restaurants relatively strongly affected by minimum wage increases in terms of their wage costs.

Our approach offers several advantages over the existing literature on price pass-through. First, unlike studies based on food-away-from-home CPI indices, where substitution of restaurants by consumers as well as food and service quality adjustment and tipping adjustments within restaurants are plausible responses to price increases, our approach is based on observing prices of an identical product in a setting with no tipping. ${ }^{14}$ Second, our geographic coverage as well as the number of minimum wage changes we study are substantially higher compared to the recent work on price pass-through of US minimum wages. We employ extensive variation in minimum wages both at the state and local level, and are also able to focus on cross-state-border comparisons (similar to Allegretto and Reich, 2018). Third, unlike all of the minimum-wage pass-through literature, we observe store-level wage rates, which allows us to assess the wage impact of minimum wage increases. McDonald's restaurants rely heavily on its Basic Crew and these workers are likely to be affected by minimum wage legislation. Our analysis is facilitated by the

studies focus on the minimum wage price effects for identical products in US retail. Renkin et al. (in press) and Leung (in press) use bar-code scanner price data from US retail stores to reach conflicting conclusions. Renkin et al. (in press) imply full price pass through, similar to previous wholesale and retail studies.

${ }^{14}$ Similar to the existing research using prices of specific fast-food items (e.g., Basker and Khan, 2016), we assume that the Big Mac price is representative of the overall price level in a store. 
fixed technology of production and thus constant labor cost share of McDonald's restaurants so that, unlike the existing literature, we do not estimate establishment-specific labor cost shares and can instead assume that labor's share in variable (marginal) costs is constant across restaurants. Fourth, information about owners of franchises and the geo-coded nature of our data allows us to measure the degree of franchise ownership concentration for various highly detailed geographical definitions of product markets. Our goal is thus to explore pass-through under varying degrees of product market power approximated by ownership concentration in order to contribute to the work on the impact of competition on pass-through summarized in Genakos and Pagliero (2019).

Finally, our analysis of the effects of minimum wage increases on McDonald's restaurant entry and exit extends the evidence offered in two recent studies: Aaronson et al. (2018) explore five state-level minimum wage increases and suggest these hikes increased both entry and exit of fast food restaurants. Luca and Luca (2017) rely on minimum wage hikes in cities located in the San Francisco Bay area and find that higher minimum wages lead to higher probability of closure (exit) for restaurants with lower customer ratings, but that they have no effect on the exit rate of top-rated restaurants and no discernible effect on entry. Our analysis covers the entire US and relies on over three hundred changes in effective minimum wages. On the other hand, it focuses on a fast food chain characterized by low entry and exit rates (see Section 2).

\section{Minimum Wages and McWages}

To quantify how minimum wage increases affect McWages (and to build the first step of our price pass-through analysis), we estimate the McWage elasticity with respect to minimum wages from our 2016-2020 data based on a linear equation conditioning on restaurant and year fixed effects: ${ }^{15}$

$$
\ln \left(\text { McWage }_{i t}\right)=\alpha+\beta \ln \left(M W_{i t}\right)+\delta_{i}+\varphi_{t}+\varepsilon_{i t}
$$

\footnotetext{
${ }^{15}$ The data allow us to estimate the elasticity of hourly wages with respect to minimum wages, not the elasticity of the wage bill. With prices increasing and sales declining, adjustments in hours worked could result in a wage-bill elasticity that would be lower than the wage-rate elasticity. However, Okrent and Alston (2012) suggest that demand for restaurant output is relatively price inelastic and Brummund (2017) finds no hours adjustments in response to minimum wage, reducing these concerns.
} 
where $M W_{i t}$ stands for the effective minimum wage (federal, state, or local) faced by a McDonald's restaurant $i$ in year $t$, and where $\delta_{i}$ and $\varphi_{t}$ represent restaurant and year fixed effects, respectively. Next, we aggregated equation (1) to the county level with county fixed effects, relying on counties with at least five observations. Using restaurant-level data in column (1) of Table 2, we uncover a 0.7 elasticity; the estimate based on county-level data in column (2) is similar. In the Appendix Table A.2, we present these specifications separately for restaurants facing minimum wage changes driven by local (city or county) minimum wage ordinances and for the majority of the data exposed to (at most) state-level minimum-wage increases. The local-variation based coefficient is somewhat smaller compared to the elasticity based on state-level variation.

Tab. 2: $\ln$ (McWages) and Minimum Wages (MW), 2016-20

\begin{tabular}{|c|c|c|c|c|}
\hline & (1) & (2) & (3) & (4) \\
\hline \multirow[t]{2}{*}{$\ln (\mathrm{MW})$} & 0.680 & 0.667 & 0.665 & 0.680 \\
\hline & $(0.053)$ & $(0.046)$ & (0.059) & (0.059) \\
\hline \multirow[t]{2}{*}{ Affected by MW Increase } & & & 0.051 & -0.057 \\
\hline & & & $(0.084)$ & $(0.078)$ \\
\hline \multirow{2}{*}{$\ln (\mathrm{MW}) *$ Affected } & & & -0.025 & 0.011 \\
\hline & & & $(0.039)$ & $(0.036)$ \\
\hline Observation Level & Restaurants & Counties & Restaurants & Counties \\
\hline Fixed Effects & \multicolumn{4}{|c|}{ Restaurant/County and Year } \\
\hline $\mathrm{N}$ & 52,281 & 2,658 & 40,739 & 2,273 \\
\hline
\end{tabular}

Note: Std. errors in parentheses. Bolded coefficients statistically significant at the $1 \%$ level based on errors clustered at the state level. We only use county-level aggregates when there are at least 5 restaurant observations per county and year.

It is natural to ask about heterogeneity in the wage effect of minimum wage hikes with respect to how binding minimum wage increases are (see, e.g., Ashenfelter and Card, 1981). In columns (3) and (4) of Table 2, we therefore estimate specifications where we additionally control for an indicator 'Affected by $M W$ Increase', which is equal to 1 when a given restaurant had to increase its wages in order to meet the new minimum wage level. The indicator stays at zero for restaurants that face no minimum wage increase or those that, as of the previous year, were already paying wages above the current increased minimum wage level. ${ }^{16}$ We interact the minimum wage

\footnotetext{
${ }^{16}$ We cannot determine the value of the 'Affected' indicator for restaurants not observed in consecutive years and also for restaurants observed in 2016 in locations that experienced an increase in minimum wages
} 
with this indicator to ask whether wages react to minimum wage hikes differently in restaurants for which minimum wage hikes are binding. The estimates suggest no such interactions; we find no statistically significant differences in wage increases driven by minimum wage hikes across the 'Affected' dimension irrespective of whether we employ restaurant- or county-level data. ${ }^{17}$

That minimum wage hikes increase wages similarly below and above the new minimum wage level is strong evidence of spillovers effects. In our case, these spillovers are not due to within-firm pay norms; they correspond to standardized jobs with fixed physical productivity and hedonic job conditions. Below, we investigate the structure of the wage reaction to minimum wages in more detail.

In the 2016-2020 McDonald's survey, we observe 15,601 instances when a given restaurant is observed both before and after a minimum wage increase, corresponding to 6,585 distinct restaurants experiencing at least one minimum wage hike at the state or local level. We focus on the evolution of pay gaps between McWages and effective minimum wages across these instances. In 39\% of minimum-wage-increase instances (in 6,094 instances), restaurants pay wages within 10 cents of the minimum wage both before and after its increase, i.e., they keep their wage rates at about the minimum wage level.

In another $13 \%$ of the instances of minimum wage increases (2,008 cases), we observe restaurants that paid a 'premium' of more than 10 cents above the old minimum wage increase their wages to pay within 10 cents of the new minimum wage. And in $11 \%$ of minimum-wage-hike instances (1,733 cases), restaurants do not change their pay, which is at least 10 cents above the new minimum wage level. Hence, in $63 \%$ of instances of minimum wage increases, the wage adjustment paths are consistent with simple neoclassical predictions: these firms only increase their wage rates when the failure to do so would make them out of compliance with the minimum wage law.

This leaves $37 \%$ of instances (5,766 cases), where restaurants follow pay paths that are broadly inconsistent with neoclassical predictions. In $12 \%$ of all minimum-pay-hike instances, restaurants that were at the old minimum wage level increased their pay to more than 10 cents

between 2015 and $2016.75 \%$ of restaurants 'Affected' in 2017 pay within 5\% of the new minimum wage level. Assuming that restaurants that pay McWages within 5\% of an increased 2016 minimum wage were 'Affected' does not qualitatively affect the estimates. We aggregate data to the county level separately for the 'affected' and the 'non-affected' restaurants and use only data cells based on at least 5 observations.

${ }^{17} \mathrm{We}$ find similar results when we separately estimate these specifications for restaurants affected by statelevel variation in minimum wages and those affected by local-level variation, see Appendix Table A.2. 
above the new minimum wage. The strongest departure from neoclassical theory is then displayed in the $25 \%$ of instances ( 3,946 cases) where restaurants stay more than 10 cents above both the old and the new minimum wage level and increase their wages (by more than 10 cents). We now focus on this group of instances, where pay level increases by almost $\$ 1$ on average, in more detail.

Overall, of McDonald's restaurants that face at least one minimum wage hike, $36 \%$ have at least once followed such a 'non-neoclassical' wage path. This corresponds to $25 \%$ of all wageadjustment paths. What predicts whether we observe a given restaurant behaving in this 'nonneoclassical' fashion at least once? Regressing an indicator for at least once following the strongly 'non-neoclassical' wage adjustment path on county fixed effects, an indicator for being companyowned, and a count of how many times a given restaurant had to face minimum wage increases in our sample, we find that both of the (precisely estimated) slope coefficients equal 0.08 . That is, company-owned restaurants are $8 \%$ more likely to at least once behave in a non-neoclassical way, and observing a restaurant one more time facing a minimum wage increase has the same effect. Within counties, we often see both 'non-neoclassical' and 'neoclassical' paths: Across the countyyear data cells with minimum wage increases where at least 10 restaurants are observed, the share of restaurants following the 'non-neoclassical' path goes from $6 \%$ at the $25^{\text {th }}$ percentile to $45 \%$ at the $75^{\text {th }}$ percentile. Thus, counties vary dramatically in the extent to which they contain nonneoclassical wage setters.

Using the 3,946 'non-neoclassical' wage adjustment paths and regressing the 'after' pay gap (relative to the new minimum wage level) on the 'before' gap, results in a coefficient of 0.89 (with standard error of 0.017 ) with an $\mathrm{R}^{2}$ of 0.5 . There is therefore a strong tendency to keep the pay gap (relative to the changing minimum wage level) constant. Appendix Figure A.3 supports this notion visually. The upper panel shows comparisons of the 'before' and 'after' pay gaps against the minimum wage level by states where state-wide minimum wages have gone up, while the lower graph shows this comparison based on minimum wage increases corresponding to local (city or county) minimum wage ordinances. Much of the data lies on the superimposed 45-degree line in all states; furthermore, most of the departures from the tendency to keep the gap constant are in the positive direction, i.e. restaurants increase their pay gap as minimum wages increase.

In sum, we find that when minimum wages increase, in a majority of instances, restaurants adjust their pay in line with simple neoclassical theory. However, a large group of restaurants deviates from these predictions; there is a tendency to keep the pay 'premium' against the evolving minimum wage fixed. Evidence of such minimum-wage 'ripple' effects corresponding to jobs with 
fixed productivity and hedonic job conditions extends the work on minimum wage spillovers (e.g., Cengiz, et al., 2019) and suggests across-employer pay norms may be important even for low-wage workers in standardized jobs. One possibility is that restaurants that pay wages substantially above the minimum wage level face lower levels of employee churn (and thus lower their costs of training). Alternatively, the non-neoclassical wage adjustment paths may be driven by local-market outside options. Exploring these potential explanations is outside the scope of our data, but an important topic for further research.

\section{Minimum Wages and Labor-Saving Technology}

McDonald's restaurants could respond to higher costs of labor by substituting technology for labor. A prime example of labor-saving technology adoption is the rapid introduction of touchscreen ordering kiosks, which save Basic Crew labor in the ordering process as they minimize crew-customer interaction prior to food delivery. According to our survey, touch-screen ordering availability increases from $20 \%$ of restaurants in 2017 to $73 \%$ in 2020. In Section 2, Table 1, we show that in a cross-sectional comparison, the presence of touch-screen ordering is not related to Big Mac prices or McWages. Our goal here is to use a difference-in-differences strategy to ask whether minimum wage increases affected the adoption of this technology, which would be consistent with restaurants substituting technology for more expensive labor. We thus estimate a version of equation (1) where the dependent variable is an indicator equal to 1 in the year when a given restaurant introduced touch-screen ordering.

The estimate presented in the first column of Table 3 suggests that higher minimum wages are negatively linked to the timing of touch-screen introductions, which is the opposite of the laborcapital substitution prediction. ${ }^{18}$ In column (3), we obtain a similar coefficient when we estimate the same specification using data aggregated to the county-level in counties with at least 5 annual observations. In the Appendix Table A.3 we show that the negative estimate is coming from state-

\footnotetext{
${ }^{18}$ In 2017, the touch-screen indicator is available for only about half of the sample. The regressions in columns (1) and (3) are based on all observations in the 2017-2020 panel when a given restaurant does not have touch-screen ordering and on the first year when touch-screen ordering is introduced; in effect, we censor restaurant observations at the moment of exit from the state 'no touch screens' as touch screens are not removed in response to minimum wages. However, the results are not sensitive to using the entire panel.
} 
level variation in minimum wages, as opposed to corresponding to variation in local minimum wage ordinances. ${ }^{19}$

Tab. 3: Touch-Screen Ordering Introduction and Minimum Wages (MW)

\begin{tabular}{lcccc}
\hline & $(1)$ & $(2)$ & $(3)$ & $(4)$ \\
\hline $\ln (\mathrm{MW})$ & -0.179 & -0.002 & -0.212 & -0.013 \\
& $(0.086)$ & $(0.031)$ & $(0.121)$ & $(0.045)$ \\
Observation Level & \multicolumn{2}{c}{ Restaurants } & \multicolumn{2}{c}{ Counties } \\
Sample Years & $2017-20$ & 2010,2020 & $2017-20$ & 2010,2020 \\
Fixed Effects & \multicolumn{2}{c}{ Restaurant and Year } & \multicolumn{2}{c}{ County and Year } \\
$\mathrm{N}$ & 25,667 & 17,570 & 1,590 & 1,115 \\
\hline
\end{tabular}

Note: Std. errors in parentheses. No coefficients statistically significant at the $1 \%$ level based on errors clustered at the state level. We only use county-level aggregates when there are at least 5 restaurant observations per county and year.

Annual variation in minimum wages and in touch-screen ordering during four years may offer an imperfect reflection of the long-term technology-investment considerations implied by minimum wage increases. We thus also estimate equation (1) using a decade-wide comparison. We assume that there were no touch-screen ordering kiosks installed in McDonald's restaurants in 2010. Instead of using annual variation during 2017-2020, we then employ the single longest difference available in our data based on stores observed in both 2010 and $2020 .{ }^{20} \mathrm{We}$ obtain precisely estimated zero coefficients in columns (2) and (4). ${ }^{21}$ We conclude that the evidence is not consistent with higher costs of labor due to minimum wages affecting touch-screen ordering introduction.

\section{Minimum Wage Price Pass-Through}

\footnotetext{
${ }^{19}$ When we estimate these specifications separately for company-owned and franchised restaurants, two groups of restaurants that share a similar aggregate evolution of touch-screen adoption in our survey, we find that the negative effect comes from the latter sub-sample, while we obtain a statistically imprecise positive coefficient for company-owned stores.

${ }^{20} \mathrm{We}$ observe restaurants operating in 2010 in our 2010-2020 panel of McDonald's locations.

${ }^{21}$ Using 2015 instead of 2010 results in almost identical estimates. We also find no statistically or economically significant interactions with the 'Affected' indicator. When we control for Covid-19 operation restrictions in 2020 and their interaction with minimum wages, we again find no significant effects.
} 
In the third step of our analysis, we provide insight into the minimum-wage price passthrough by taking advantage of the 2016-2020 data on prices and wages from each restaurant. We quantify the relationship between wage variation driven by minimum wage increases and prices, i.e., we estimate a two-stage least squares regression of prices on wages where wages are instrumented using minimum wages. The first stage of our system, corresponding to equation (1), was presented in Table 2. The second stage is given by the following equation:

$$
\ln \left(\text { BigMacPrice }_{i t}\right)=\alpha+\beta \ln \left(\text { McWage }_{i t}\right)+\delta_{i}+\varphi_{t}+\varepsilon_{i t},
$$

where $\ln$ (BigMacPrice) $_{i t}$ stands for the logarithm of the price of the Big Mac sandwich in a McDonald's restaurant $i$ in year $t$, and where we again control for both year and restaurant fixed effects. In columns (1) and (2) of Table 4, we present these 2SLS specifications corresponding to equation (2) estimated from restaurant- and county-level data, respectively.

Tab. 4: $\ln$ (BigMacPrice) and Instrumented McWages, 2016-20

\begin{tabular}{|c|c|c|c|c|}
\hline & (1) & (2) & (3) & (4) \\
\hline \multirow[t]{2}{*}{ IVed In(McWage) } & 0.202 & 0.194 & 0.200 & 0.186 \\
\hline & $(0.043)$ & $(0.057)$ & $(0.057)$ & $(0.073)$ \\
\hline \multirow[t]{2}{*}{ Affected by MW Increase } & & & -0.051 & -0.049 \\
\hline & & & $(0.024)$ & $(0.047)$ \\
\hline \multirow[t]{2}{*}{ IVed In(McWage)*Affected } & & & 0.022 & 0.022 \\
\hline & & & $(0.020)$ & $(0.020)$ \\
\hline Observation Level & Restaurants & Counties & Restaurants & Counties \\
\hline Fixed Effects & \multicolumn{4}{|c|}{ Restaurant/County and Year } \\
\hline $\mathrm{N}$ & 52,281 & 2,658 & 40,739 & 2,273 \\
\hline
\end{tabular}

Note: Std. errors in parentheses. The first stage for $\ln$ (McWages) is presented in Table

2. Bolded coefficients statistically significant at the $1 \%$ level based on errors clustered at the state level. We only use county-level aggregates when there are at least 5 restaurant observations per county and year.

The elasticity of prices with respect to wage increases driven by minimum wage hikes is 0.2. Columns (3) and (4) then present the specifications allowing for the wage effect to operate differently for restaurants facing binding minimum wage increases. ${ }^{22}$ In Table 2, we found no

\footnotetext{
${ }^{22}$ The first stage for the $\ln (M c \text { Wage })^{*}$ Affected interaction term is not shown.
} 
statistically significant differences in wage increases driven by minimum wage hikes across the 'Affected' dimension. Here, we find no such interaction in the relationship between prices and wage increases driven by minimum wages.

The 'structural' $\ln ($ McWage) coefficient in Table 4 suggests a labor cost share of about 0.2 , which, together with the first-stage wage elasticity with respect to minimum wages of about 0.7 , implies a price pass-through of 0.14 . This is indeed born out in Table 5, where we present the central object of the minimum-wage price pass-through literature - the reduced-form relationship between prices and minimum wages:

$$
\ln \left(\text { BigMacPrice }_{i t}\right)=\alpha+\beta \ln \left(M W_{i t}\right)+\delta_{i}+\varphi_{t}+\varepsilon_{i t}
$$

Tab. 5: $\ln$ (BigMacPrice) and Minimum Wages (MW), 2016-20

\begin{tabular}{|c|c|c|c|c|}
\hline & (1) & (2) & (3) & (4) \\
\hline \multirow[t]{2}{*}{$\ln (\mathrm{MW})$} & 0.138 & 0.124 & 0.131 & 0.127 \\
\hline & $(0.031)$ & $(0.042)$ & $(0.041)$ & $(0.052)$ \\
\hline \multirow[t]{2}{*}{ Affected by MW Increase } & & & -0.042 & -0.043 \\
\hline & & & $(0.027)$ & $(0.033)$ \\
\hline \multirow[t]{2}{*}{$\ln (\mathrm{MW}) *$ Affected } & & & 0.017 & 0.017 \\
\hline & & & $(0.011)$ & $(0.014)$ \\
\hline \multirow{2}{*}{$\begin{array}{l}\text { Observation Level } \\
\text { Fixed Effects }\end{array}$} & Restaurants & Counties & Restaurants & Counties \\
\hline & \multicolumn{4}{|c|}{ Restaurant/County and Year } \\
\hline $\mathrm{N}$ & 52,281 & 2,659 & 40,739 & 2,273 \\
\hline
\end{tabular}

Note: Std. errors in parentheses. Bolded coefficients statistically significant at the $1 \%$ level based on errors clustered at the state level. We only use county-level aggregates when there are at least 5 restaurant observations per county and year.

That restaurants, which already paid a wage rate above the newly increased minimum wage level, increase their wages similarly to restaurants that were paying below the new minimum wage level in the previous year is consistent with the lack of an interaction with being 'Affected' estimated in Table 5. The estimates based on restaurant-level data are again highly similar to those based on county aggregates. When we estimated the specifications shown in Tables 4 and 5 separately for restaurants facing local minimum wage changes and for the majority of the data 
exposed to, at most, state-level minimum-wage increases, we obtained similar, statistically indistinguishable results (see Appendix Tables A.4 and A.5).

Our estimated price pass-through elasticity is higher than the 0.1 elasticity typically found in previous studies discussed in Section 3. Taking the 0.2 coefficient from Table 4 as the value of the labor cost share implies (by indirect least squares logic) a full price pass through. Under the higher 30\% labor costs share estimate of Dube et al. (2010), if labor costs increases were to be passed through fully into prices, one would expect prices to increase by $3 \%$ for every $10 \%$ increase in minimum wages times the minimum wage elasticity of the wage bill. In our case, $30 \%$ of the 0.68 'first stage' minimum wage elasticity of McWages equals 0.2. Our reduced-form price passthrough coefficient of 0.14 would thus imply a $70 \%$ pass-through. Overall, we conclude that our evidence is consistent with near-full price pass through of minimum wages in McDonald's restaurants.

One way to measure the purchasing power of McWages is to express them in the number of Big Macs an hour of Basic Crew work can buy. This is a measure of the "real wage". The precisely estimated elasticity of Big Macs per hour of work with respect to minimum wages (which is simply the difference between the elasticity of the McWage and the Big Mac Prince with respect to the minimum wage) is 0.54 , which is less than the $0.68 \mathrm{McWage}$ elasticity (shown in Table 2). Our evidence thus provides support for the notion that real income increases of low-wage workers brought about by minimum wages hikes may be lower than expected (MaCurdy, 2015).

In the final step of our price pass-through analysis, we explore heterogeneity in passthrough related to the degree of product market competition approximated by local ownership concentration. Figure A.2 in the Appendix visualizes the extent of variation across counties (covered by our McWage survey) in the 2018 degree of franchise ownership concentration as summarized by the Herfindahl-Hirschman Index (HHI). Since counties with only a few restaurants may imply a single owner, where we employ the HHI variation, we only use counties (product markets) with over 5 McDonald's. We do not observe changes in ownership concentration over time and assume that the market-level ownership structure is stable; hence, the HHI levels are absorbed by the estimated fixed effects. Instead of exploring the interaction with the 'Affected' indicator, we estimate equations (1) and (2) with HHI-index interactions. We find no evidence of 
any first- or second-stage interactions with ownership concentration. ${ }^{23}$ The estimates are shown in the Appendix Table A.6, which also lists specifications estimated separately for restaurants affected by state- and local-level minimum wage variation. ${ }^{24}$

\section{Minimum Wages and Restaurant Entry and Exit}

In the final step of our inquiry, we ask whether our main analysis is affected by compositional effects linked to minimum wage increases. We employ a listing of all McDonald's restaurants from 2010 to 2020 to provide evidence on the effects of minimum wages on McDonald's restaurant entry and exit.

Restaurants that are unable to pass through cost increases induced by minimum wage hikes onto their customers may no longer be profitable and may have to close down. It is also plausible that the higher purchasing power of customers generated by minimum wage increases supports demand for McDonald's products and leads to new restaurants opening. If minimum wages affected the composition of McDonald's restaurants in operation, this would have implications for analyses based on such selected samples. To assess whether minimum wage increases affect McDonald's restaurant closure, we estimate a specification relating the probability of restaurant exit to minimum wages at the county level, conditioning on county and year fixed effects: ${ }^{25}$

$$
\text { Exit }_{i t}=\alpha+\beta \ln \left(M W_{i t}\right)+\delta_{i}+\varphi_{t}+\varepsilon_{i t} .
$$

Here, Exit $t_{i t}$ represents the exit rate in county $i$ in year $t$ and $M W_{i t}$ again stands for the corresponding effective minimum wage level. Next, we compute the entry regression by replacing the exit rate with an entry rate, Entry ${ }_{i t}{ }^{26}$

\footnotetext{
${ }^{23}$ These results are robust to excluding company-owned restaurants. We present results based on counties, but obtain similar effects when using markets defined as $25 \mathrm{~km}$ radius areas around each restaurant.

${ }^{24}$ When we estimate our specifications separately for markets (counties) in the highest/lowest tercile of county population and of market-level number of competitors (proxied by the number of Burger King, KFC and Wendy's restaurants), we again obtain statistically indistinguishable results.

${ }^{25}$ The results are not sensitive to using city fixed effects for locations with local minimum wage ordinances to the extent that these do not correspond to counties.

${ }^{26} \mathrm{We}$ infer these rates from the presence of a restaurant in the annual listing from the fall of each year.
} 
Since our 2010-2020 panel offers substantially more variation than our 2016-2020 McDonald's survey, we present separate estimates for the restaurants affected at most by state-wide increases in minimum wages and for restaurants facing increases in local (city or county) minimum wages. We also explore another identification strategy, following Dube et al. (2010). ${ }^{27}$

The estimates presented in Table 6 suggest no statistically significant effects of minimum wages on entry or exit. The exit coefficient in column (1) corresponds to a precisely estimated zero effect; the 0.013 entry coefficient in column (5), while statistically indistinguishable from zero, is no longer small. ${ }^{28}$ These results are insensitive to specification changes. We estimated these specifications separately for restaurants located in areas (cities or counties) that, within our sample, introduced or increased a local minimum wage. This allowed us to ask whether minimum wage effects in these locations are different from the majority of the data that is covered only by (potential) increases in state-wide minimum wages. We obtained quantitatively as well as qualitatively indistinguishable results based on the two types of minimum-wage variation.

Tab. 6: Minimum Wage (MW) Effects on McDonald's Entry and Exit, 2010-2020

\begin{tabular}{lcccccccc}
\hline Outcome Variable [mean] & \multicolumn{4}{c}{ Exit [0.01] } & \multicolumn{4}{c}{ Entry [0.01] } \\
& $(1)$ & $(2)$ & $(3)$ & $(4)$ & $(5)$ & $(6)$ & $(7)$ & $(8)$ \\
\hline In(MW) & -0.002 & -0.010 & 0.003 & -0.014 & 0.013 & 0.018 & 0.007 & -0.010 \\
& $(0.004)$ & $(0.032)$ & $(0.022)$ & $(0.060)$ & $(0.007)$ & $(0.014)$ & $(0.015)$ & $(0.051)$ \\
MW Variation Level & State & Local & State & Local & State & Local & State & Local \\
Observation Level & Restaurants & County Pairs & Restaurants & County Pairs \\
Fixed Effects & County and Year & County-Pair-Year & County and Year & County-Pair- \\
& \multicolumn{4}{c}{ and County } \\
$\mathrm{N}$ & 132,646 & 8,141 & 15,653 & 1,605 & 132,579 & 8,039 & 15,669 & 1,605 \\
\hline
\end{tabular}

Note: Std. errors in parentheses based on clustering at the state (columns (1), (2), (5), (6)) or county level. In column (3), (4), (7), and (8) the data correspond to contiguous county pairs straddling a state border or a border between counties affected by local minimum wage ordinances and their neighboring counties.

We also obtain similar estimates based on county-level aggregates when we employ the identification strategy of Dube et al. (2010), i.e., when we study gaps in entry or exit rates and in

\footnotetext{
${ }^{27}$ This strategy did not lead to precisely estimated coefficients when applied to the 2016-20 data. To illustrate these imprecise estimates, we include them in the last two columns of Table A.5.

${ }^{28}$ The standard deviation of $\ln (\mathrm{MW})$ in the entry/exit panel is 0.14 . At a 0.013 slope, changing the minimum wage by one standard deviation would increase the entry rate by 0.002 , about one-fifth of its average.
} 
minimum wages within pairs of contiguous counties straddling a common state border. The identifying assumption corresponding to the Dube et al. (2010) strategy is that minimum wage differences within the county pairs are uncorrelated with the corresponding differences in residual entry/exit rates.

It is possible that any effects are only visible with a significant delay, especially given the low average entry and exit rates of McDonald's restaurants. The short nature of our panel does not allow us to explore the dynamics of the minimum wage effect in detail, but when we use longer differences (of two to five years) within our decade-long panel of entry and exit, we never find statistically significant effects, none of the coefficients are larger than those presented in Table 6, and most of the specifications result in precisely estimated zeros. Finally, we also obtain precisely estimated zero coefficients when using the longest comparison offered by our panel, i.e., when relying only on the decade-long gap between the earliest and the latest entry or exit rates available. This suggests longer-term effects are not present either. ${ }^{29}$

Overall, our evidence, which is based on a broader geographical coverage and more extensive minimum wage variation compared to Card and Krueger (1994), Aaronson et al. (2018) and Luca and Luca (2017), but which corresponds to restaurants that display generally low churn rates, suggests there are no effects of minimum wages (including those introduced at the local level) on McDonald's restaurant closure or entry. This finding is consistent with much of the recent literature suggesting no or small employment effects of minimum wages (e.g., Cenzig et al., 2019) and implies that our analyses presented above are not affected by compositional effects. ${ }^{30}$

\footnotetext{
${ }^{29}$ Using the 2016-2020 wage data, we also interacted the minimum wage with the 'Affected' indicator (see Section 4) and found no evidence of such interactions affecting entry/exit. Similarly, we have uncovered no support for any ownership concentration interactions of the minimum wage effects on entry or exit of restaurants. We have additionally implemented an estimator based on matching a city with a local minimum wage increase to a similar city (without such increase) within a state or to the nearest similar city. These results also imply no effect on either entry or exit.

${ }^{30}$ To the extent that we find positive entry effects and zero exit effects, these are consistent with reallocation towards major franchise chains from smaller firms in line with the evidence in Dustmann et al. (2020).
} 


\section{Conclusions}

Minimum wages powerfully affect service occupations. In 2016, almost half of McDonald's Basic Crew was paid the effective minimum wage. We find a 0.68 elasticity of McWages with respect to minimum wages and document that McDonald's restaurants increase wages in response to minimum wage hikes similarly regardless of whether minimum wage increases are binding at the restaurant level. In response to minimum wage hikes, a large group of restaurants keep their wage 'premium' above the minimum wage constant. Evidence on such minimum-wage 'ripple' effects corresponding to jobs with fixed productivity and hedonic job conditions extends the work on minimum wage spillovers and suggests across-employer pay norms related to employee churn, something that Lester (1960) and Kaufman (2010) have emphasized in the institutional literature.

We also find that McDonald's restaurants do not introduce touch-screen ordering, a potential labor-saving technology, in response to increases in labor costs driven by minimum wage hikes. Moreover, we find restaurants are able to pass nearly all of such labor cost increases onto their customers in the form of higher Big Mac prices. As a result, our evidence indicates that the elasticity of Big Macs per hour of Basic Crew work (a real wage measure) is 0.54 , which is substantial, but about one-fifth lower than the $0.68 \mathrm{McWage}$ elasticity.

Strong price pass-through is consistent with our finding of no effect of higher labor costs due to minimum wages on restaurant closures and with the evidence that higher minimum wages do not speed up the introduction of labor-saving technology. We cannot reject non-zero employment elasticities, but our McDonald's evidence, based on highly consistent comparisons across time and space, is in line with the growing literature suggesting that recent minimum wage increases did not affect employment in the non-tradable sector, including restaurants and retail, a sector that employs the majority of minimum wage workers in the US.

Finally, we uncover similar minimum wage effects when using variation in minimum wages driven by state-wide minimum wage increases and when relying on variation brought about by local (city or county) minimum wage increases. Our evidence thus suggests that cities may be able to tailor minimum wage policy to local economic conditions. 


\section{References}

Aaronson, D. (2001) "Price Pass-Through and the Minimum Wage," The Review of Economics and Statistics, 83(1), 158-169.

Aaronson, D., and E. French (2007) "Product Market Evidence on the Employment Effects of the Minimum Wage," The Journal of Labor Economics, 25(1), 167-200.

Aaronson, D., French, E., and J. MacDonald (2008) "The Minimum Wage, Restaurant Prices, and Labor Market Structure," The Journal of Human Resources, 43(3), 688-720.

Aaronson, D., French, E., Sorkin, I., and T. To (2018) "Industry Dynamics and the Minimum Wage: A Putty-Clay Approach," International Economic Review, 59: 51-84.

Aaronson, D., Hu, L., A. Rajan (2020) "How Much Did the Minimum Wage Drive Real Wage Growth During the Late 2010s?" Chicago Fed Letter, Federal Reserve Bank of Chicago, issue 435.

Aaronson, D., and B.J. Phelan (2019) "Wage Shocks and the Technological Substitution of Low-wage Jobs," The Economic Journal, 129(617): 1-34.

Allegretto, S., and M. Reich (2018) "Are Local Minimum Wages Absorbed by Price Increases? Estimates from Internet-Based Restaurant Menus,” ILR Review, 71(1): 35-63.

Ashenfelter, O., Ashmore, D., Baker, J.B., and S.-M. McKernan (1998) "Identifying the Firm-Specific Cost Pass-Through Rate,” Federal Trade Commission, Working Paper No. 217.

Ashenfelter, O., and D.E. Card (1981) "Using Longitudinal Data to Estimate the Employment Effects of the Minimum Wage," Discussion Paper No. 98, Centre for Labour Economics, London School of Economics.

Ashenfelter, O., and S. Jurajda (2020) "How Low Are U.S. Wage Rates? A McWage Comparison"

Basker, E., and M.T. Khan (2016) “Does the Minimum Wage Bite into Fast-Food Prices?" Journal of Labor Research, 37(2): 129-148.

Brummund, P. (2017) “How Do Restaurants Pay For the Minimum Wage?” working paper

Card, D., and A. Krueger (1994) "Minimum Wages and Employment: A Case Study of the Fast Food Industry in New Jersey \& Pennsylvania," American Economic Review 84(4): 772-93.

Card, D. and A. Krueger (1995) Myth and Measurement: The New Economics of the Minimum Wage, Princeton University Press.

Cenzig, D., Dube, A., Lindner, A., Zipperer, B. (2019) "The Effect of Minimum Wages on Low-Wage Jobs," Quarterly Journal of Economics, 134(3): 1405-1454.

DellaVigna, S., and M. Gentzkow (2019) "Uniform Pricing in US Retail Chains," Quarterly Journal of Economics, 134(4): 2011-2084. 
Dube, A., William, L.T., and M. Reich (2010) "Minimum Wage Effects Across State Borders: Estimates Using Contiguous Counties," Review of Economics and Statistics, 92(4): 945-964.

Dube, A., and A. Lindner (2020) “City Limits: What do Local-Area Minimum Wages Do?”

Dustmann, C., Lindner, A., Schoenberg, U., Umkehrer, M., and P. vom Berge (2020) "Reallocation Effects of the Minimum Wage," CReAM Discussion Paper 07/20.

Flinn, C.J. (2006) "Minimum Wage Effects on Labor Market Outcomes under Search, Matching, and Endogenous Contact Rates," Econometrica, 74: 1013-1062.

Fullerton, D., and G. E. Metcalf (2002) "Tax Incidence," in, Auerbach, A. J. and M. Feldstein, (eds.), Handbook of Public Economics, Vol. 4, pp. 1787-1872. North-Holland, Amsterdam.

Genakos, C., and M. Pagliero (2019) "Competition and Pass-Through: Evidence from Isolated Markets," CEPR Discussion Paper No. DP13882

Hau, H., Huang, Y., and G. Wang (2020) "Firm Response to Competitive Shocks: Evidence from China's Minimum Wage Policy,” Review of Economic Studies, 87(6): 2639-2671.

Hirsch, B.T., B.E. Kaufman, and T. Zelenska (2015) "Minimum Wage Channels of Adjustment," Industrial Relations, 54(2): 199-239.

Kaufman, B.E. (2010) "Institutional Economics and the Minimum Wage: Broadening the Theoretical and Policy Debate," Industrial and Labor Relations Review, 63: 427-453.

Krueger, A.B. (1991) "Ownership, Agency, and Wages: An Examination of Franchising in the Fast Food Industry," The Quarterly Journal of Economics, 106(1): 75-101.

Lester, R.A. (1960) “Employment Effects of Minimum Wages," Industrial and Labor Relations Review 13: 254-264.

Leung, J. (in press) "Minimum Wage and Real Wage Inequality: Evidence from Pass-Through to Retail Prices" Review of Economics and Statistics.

Luca, D.L., and M. Luca (2017) "Survival of the Fittest: The Impact of the Minimum age on Firm Exit," Harvard Business School Working Paper 17-088.

MaCurdy, T. (2015) "How Effective Is the Minimum Wage at Supporting the Poor?," Journal of Political Economy, 123(2): 497-545

Manning, A. (2003) Monopsony in Motion: Imperfect Competition in Labor Markets, Princeton University Press.

Okrent, A., and J. Alston (2012) "The Demand for Disaggregated Food-Away-from-Home and Food-atHome Products in the US,” USDA-ERS Economic Research Report No. 139.

Parsley, D. C., and S.-J. Wei (2007) "A Prism into the PPP Puzzles: The Micro-Foundations of Big Mac Real Exchange Rates,” The Economic Journal, 117(523): 1336-1356. 
Phelan, B.J. (2019) "Hedonic-Based Labor Supply Substitution and the Ripple Effect of Minimum Wages," Journal of Labor Economics, 37(3): 905-947.

Pless, J., and A. van Benthem (2019) "Pass-Through as a Test for Market Power: An Application to Solar Subsidies," American Economic Journal: Applied Economics, 11(4): 367-401.

Renkin, T., Montialouxc, C., and M. Siegenthaler (in press) "The Pass-through of Minimum Wages into US Retail Prices: Evidence from Supermarket Scanner Data," Review of Economics and Statistics.

Weyl, E.G., and M. Fabinger (2013) "Pass-Through as an Economic Tool: Principles of Incidence under Imperfect Competition,” Journal of Political Economy, 121(3): 528-583. 


\section{APPENDIX}

Figure A.1: Annual Entry and Exit Rates (in \%) of McDonald's Restaurants

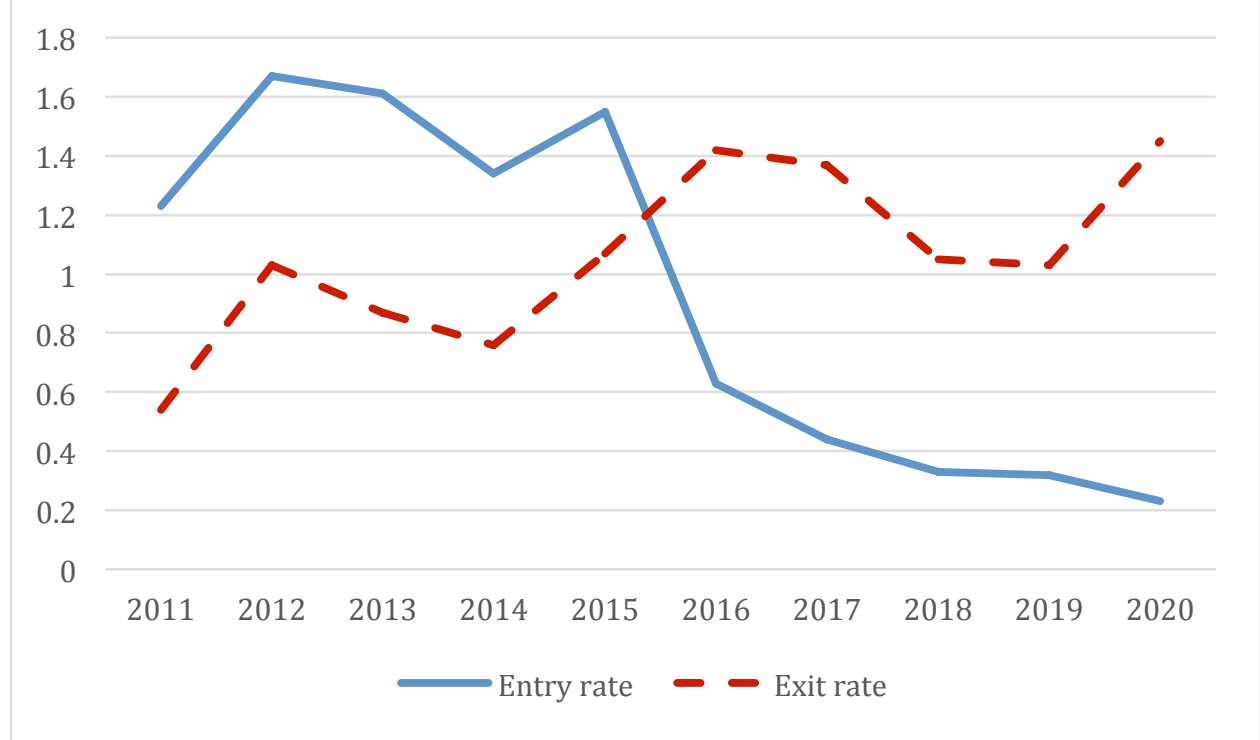

Tab. A.1: McDonald's Survey Descriptive Characteristics

\begin{tabular}{lccccc}
\hline & 2016 & 2017 & 2018 & 2019 & 2020 \\
\hline $\operatorname{In}($ BigMacPrice) & 1.489 & 1.520 & 1.552 & 1.579 & 1.576 \\
& $(0.099)$ & $(0.106)$ & $(0.102)$ & $(0.103)$ & $(0.106)$ \\
$\ln ($ McWage) & 2.136 & 2.179 & 2.216 & $2 . .256$ & 2.298 \\
& $(0.119)$ & $(0.148)$ & $(0.167)$ & $(0.187)$ & $(0.201)$ \\
$\ln ($ Effective Minimum Wage) & 2.085 & 2.121 & 2.143 & 2.171 & 2.201 \\
& $(0.114)$ & $(0.149)$ & $(0.172)$ & $(0.197)$ & $(0.217)$ \\
Restaurant is company owned & 0.109 & 0.100 & 0.095 & 0.097 & 0.900 \\
on highway & 0.119 & 0.111 & 0.116 & 0.119 & 0.117 \\
on parkway & 0.024 & 0.023 & 0.023 & 0.023 & 0.023 \\
free standing & 0.862 & 0.857 & 0.860 & 0.865 & 0.876 \\
has touch-screen ordering & -- & 0.203 & 0.533 & 0.724 & 0.726 \\
Crew (not manager) answered & 0.050 & 0.031 & 0.035 & 0.032 & 0.043 \\
$\mathrm{~N}$ & 11,365 & 10,873 & 10,408 & 10,003 & 9,713 \\
\hline
\end{tabular}

Note: Standard deviations in parentheses. 
Figure A.2: McDonald's Ownership Concentration across U.S. Counties, 2018

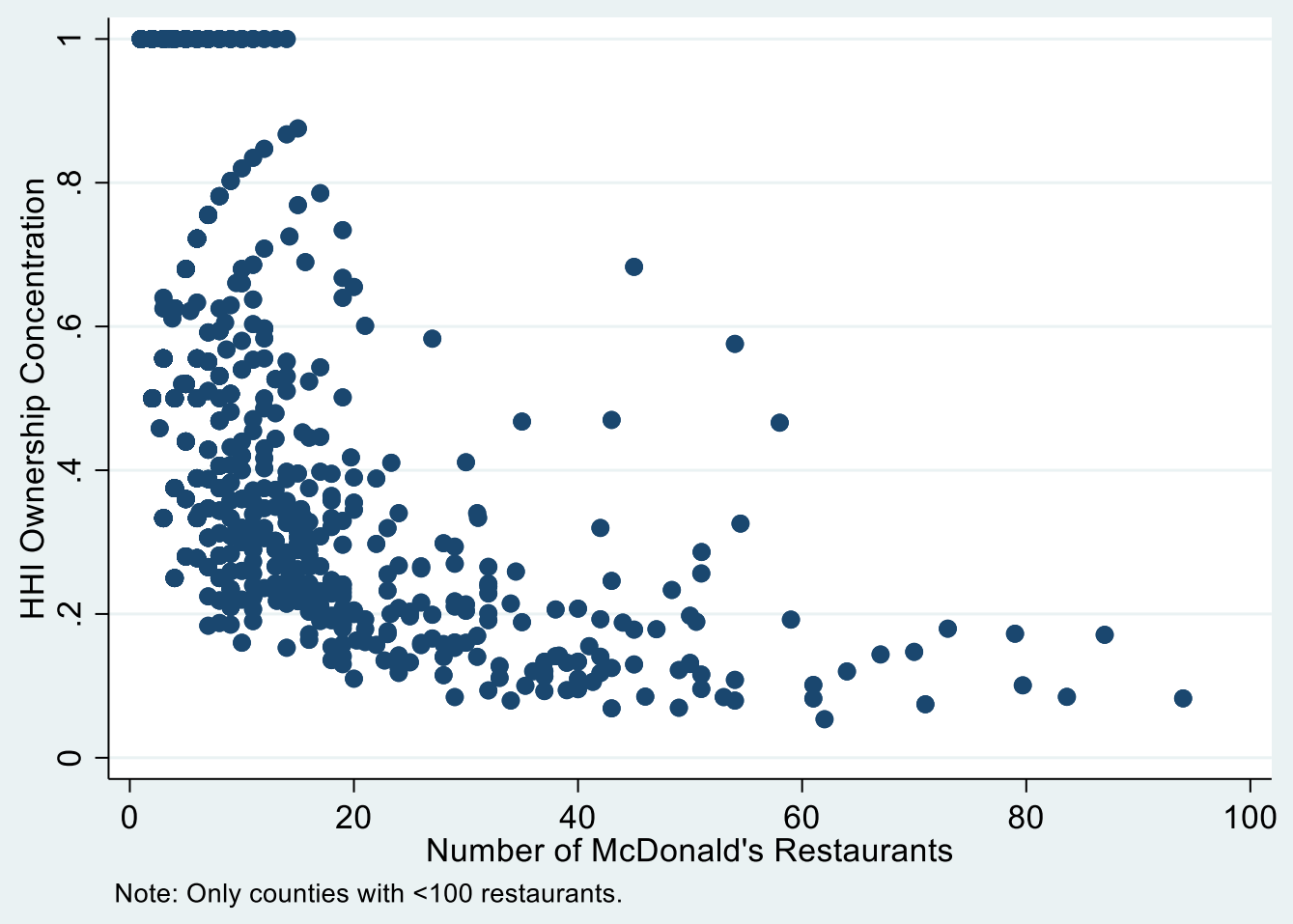


Figure A.3: The Gap between \$McWages and \$Minimum Wages (MW) Before/After MW Hikes in the $25 \%$ of Instances of 'Non-Neoclassical' Wage Adjustment
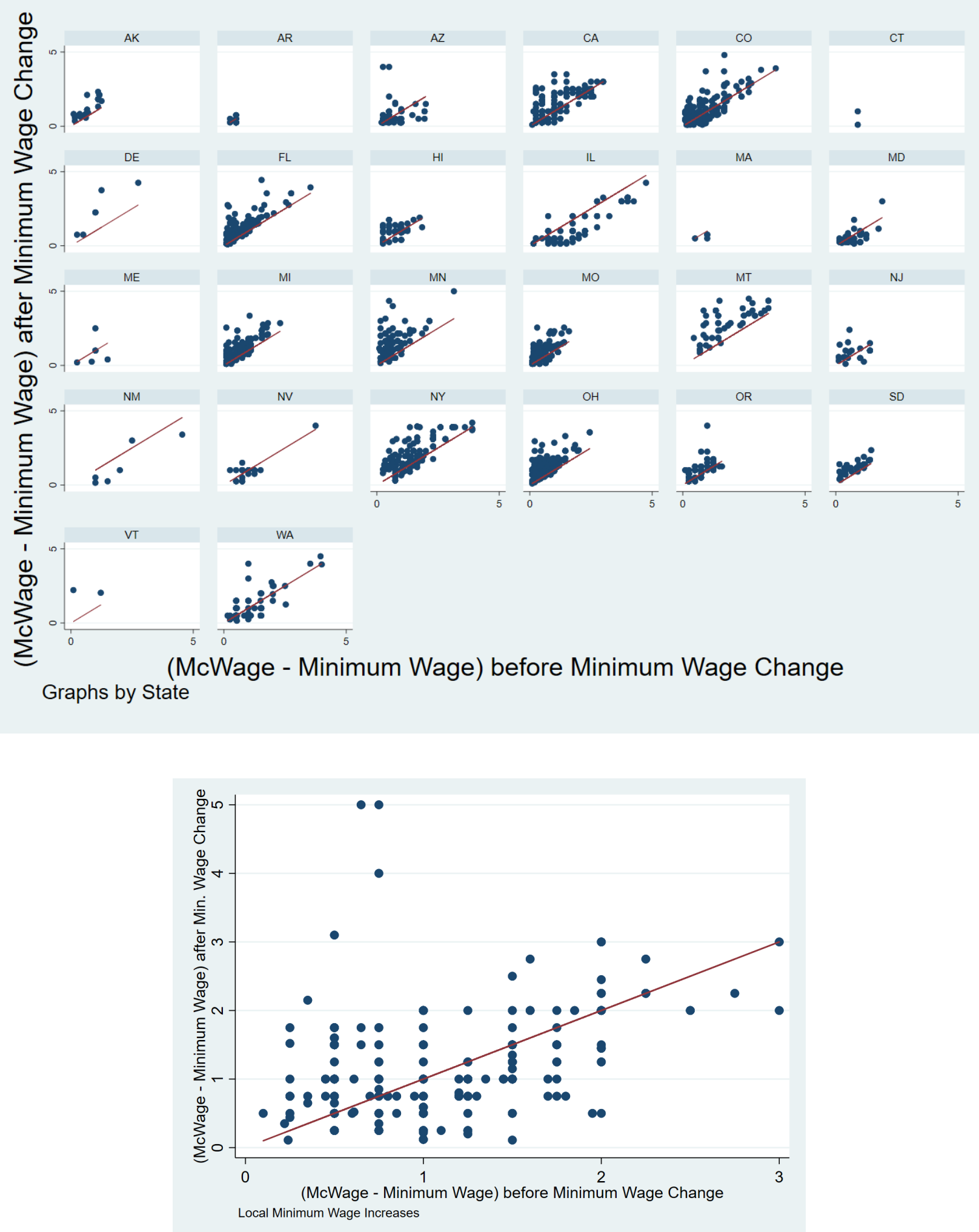
Table A.2: $\ln ($ McWage) and Minimum Wages (MW), 2016-20

\begin{tabular}{|c|c|c|c|c|}
\hline & (1) & (2) & (3) & (4) \\
\hline \multirow[t]{2}{*}{$\ln (\mathrm{MW})$} & 0.685 & 0.503 & 0.666 & 0.556 \\
\hline & $(0.009)$ & $(0.032)$ & $(0.018)$ & $(0.045)$ \\
\hline \multirow[t]{2}{*}{ Affected by MW Increase } & & & 0.033 & 0.013 \\
\hline & & & $(0.019)$ & $(0.077)$ \\
\hline \multirow[t]{2}{*}{$\ln (\mathrm{MW}) *$ Affected } & & & -0.017 & -0.013 \\
\hline & & & $(0.009)$ & (0.031) \\
\hline MW Variation Level & State & Local & State & Local \\
\hline Observation Level & \multicolumn{4}{|c|}{ Restaurants } \\
\hline Fixed Effects & \multicolumn{4}{|c|}{ Restaurant and Year } \\
\hline $\mathrm{N}$ & 49,750 & 2,530 & 39,171 & 1,568 \\
\hline
\end{tabular}

Note: Std. errors in parentheses. Bolded coefficients statistically significant at the $1 \%$ level based on errors clustered at the state level.

Tab. A.3: Touch-Screen Ordering Introduction and Minimum Wages (MW), 2017-20

\begin{tabular}{lcccc}
\hline & $(1)$ & $(2)$ & $(3)$ & $(4)$ \\
\hline In(MW) & -0.200 & 0.250 & -0.227 & 0.042 \\
& $(0.098)$ & $(0.262)$ & $(0.132)$ & $(0.445)$ \\
MW Variation Level & State & Local & State & Local \\
Observation Level & \multicolumn{2}{c}{ Restaurants } & \multicolumn{2}{c}{ Counties } \\
Fixed Effects & Restaurant and Year & County and Year \\
$\mathrm{N}$ & 24,409 & 1,258 & 1,540 & 83 \\
\hline
\end{tabular}

Note: Std. errors in parentheses. Bolded coefficients statistically significant at the $1 \%$ level based on errors clustered at the state level. We only use county-level aggregates when there are at least 5 restaurant observations per county and year.

Tab. A.4: $\ln$ (BigMacPrice) and Minimum Wages (MW), 2016-20

\begin{tabular}{lcccc}
\hline & $(1)$ & $(2)$ & $(3)$ & $(4)$ \\
& \multicolumn{3}{c}{ Second Stage } & \multicolumn{2}{c}{ Reduced } & Form \\
\hline In(MW) & \multicolumn{5}{c}{$\mathbf{0 . 1 4 7}$} & 0.048 \\
& $\mathbf{0 . 2 1 5}$ & 0.108 & $(0.036)$ & $(0.050)$ \\
In(McWage) IVed & $(0.048)$ & $(0.127)$ & \\
& State & Local & State & Local \\
MW Variation Level & \multicolumn{4}{c}{ Restaurants } \\
Observation Level & \multicolumn{4}{c}{ Restaurant and Year } \\
Fixed Effects & 49,750 & 2,530 & 49,750 & 2,530 \\
$\mathrm{~N}$ & &
\end{tabular}

Note: Std. errors in parentheses. Bolded coefficients statistically significant at the $1 \%$ level based on errors clustered at the state level. 
Tab. A.5: $\ln ($ BigMacPrice) and Minimum Wages (MW), 2016-20

\begin{tabular}{|c|c|c|c|c|c|c|c|}
\hline & (1) & (2) & (3) & (4) & $(5)$ & (6) & (7) \\
\hline \multirow[t]{2}{*}{$\ln (\mathrm{MW})$} & 0.138 & 0.133 & 0.105 & 0.131 & 0.021 & 0.127 & 0.184 \\
\hline & $(0.031)$ & $(0.043)$ & $(0.081)$ & (0.059) & $(0.060)$ & (0.330) & $(0.138)$ \\
\hline \multirow[t]{2}{*}{ Affected by MW Increase } & & 0.024 & -0.074 & -0.050 & 0.010 & -0.001 & 0.066 \\
\hline & & $(0.013)$ & $(0.039)$ & $(0.040)$ & $(0.086)$ & $(0.491)$ & $(0.367)$ \\
\hline \multirow[t]{2}{*}{$\ln (\mathrm{MW}) *$ Affected } & & -0.056 & -0.190 & 0.021 & -0.006 & -0.007 & -0.028 \\
\hline & & $(0.029)$ & $(0.100)$ & $(0.017)$ & $(0.034)$ & $(0.187)$ & $(0.151)$ \\
\hline MW Variation Level & All & State & Local & State & Local & State & Local \\
\hline Observation Level & \multicolumn{3}{|c|}{ Restaurants } & \multicolumn{2}{|c|}{ Counties } & \multicolumn{2}{|c|}{ County Pairs } \\
\hline Fixed Effects & \multicolumn{3}{|c|}{ Restaurant and Year } & \multicolumn{2}{|c|}{ County and Year } & \multicolumn{2}{|c|}{$\begin{array}{c}\text { County-Pair-Year } \\
\text { and County }\end{array}$} \\
\hline $\mathrm{N}$ & 52,281 & 39,171 & 1,568 & 2,199 & 299 & 1,429 & 1,045 \\
\hline
\end{tabular}

Note: Std. errors in parentheses. Bolded coefficients statistically significant at the $1 \%$ level based on errors clustered at the state level. In column (6) and (7) the data (and clustering) correspond to county observations for each contiguous county pair straddling a state border or a border between counties affected by local minimum wage ordinances and their neighboring counties. We only use county-level aggregates when there are at least 5 restaurant observations per county and year.

Tab. A.6: Price Pass-Through of Minimum Wages (MW) into $\ln$ (BigMacPrice) during 2016-2020

\begin{tabular}{|c|c|c|c|c|}
\hline \multirow{3}{*}{$\begin{array}{l}\text { Outcome variable } \\
\ln (\mathrm{MW})\end{array}$} & (1) & (2) & (3) & (4) \\
\hline & \multicolumn{2}{|c|}{$\begin{array}{l}\text { First Stage } \\
\ln (\text { McWage) }\end{array}$} & \multicolumn{2}{|c|}{$\begin{array}{l}\text { Second Stage } \\
\text { In(BigMacPrice) }\end{array}$} \\
\hline & 0.685 & 0.503 & & \\
\hline & (0.009) & $(0.032)$ & & \\
\hline \multirow[t]{2}{*}{ In(McWage) IVed } & & & 0.219 & 0.111 \\
\hline & & & $(0.015)$ & (0.090) \\
\hline \multirow[t]{2}{*}{$\ln (\mathrm{MW}) * \mathrm{HHI}$} & -0.004 & -0.329 & & \\
\hline & $(0.015)$ & $(0.213)$ & & \\
\hline \multirow[t]{2}{*}{ In(McWage)*HHI IVed } & & & -0.011 & -0.037 \\
\hline & & & $(0.022)$ & (0.179) \\
\hline MW Variation Level & State & Local & State & Local \\
\hline Observation Level & \multicolumn{4}{|c|}{ Restaurants } \\
\hline Fixed Effects & \multicolumn{4}{|c|}{ Restaurant and Year } \\
\hline $\mathrm{N}$ & 31,383 & 2,348 & 31,383 & 2,348 \\
\hline
\end{tabular}

Note: Std. errors in parentheses. Bolded coefficients statistically significant at the $1 \%$ level based on errors clustered at the state level. $\mathrm{HHI}$ stands for the county-level Herfindahl-Hirschman Index of McDonald's ownership concentration. We only use data from counties with at least 5 restaurant observations per county and year. 